\title{
The Influence of Transfer Plates on the Lateral Behaviour of Apartment Buildings
}

\author{
S. S. Balasuriya, K. M. K. Bandara, S. D. Ekanayake, M. T. R. Jayasinghe
}

\begin{abstract}
The skylines in the major cities of Sri Lanka are fast changing with many apartment buildings being constructed. One of the primary requirements is the provision of car parking for which the lower floors are generally used. The car parks will have a certain grid requirement for vertical load carrying members primarily arising due to guidelines specified in building regulations. Often, this grid arrangement is not suitable for apartments which generally consist of concrete walls that can become part of the partition wall system of the apartments. Therefore, it is usual to have transfer girders or a transfer plate to allow acceptable load paths for the vertical loads. When transfer plates are used in tall apartment buildings, the wind induced acceleration could be an issue that needs careful consideration. In this paper, it is shown that the transfer plates can be used as outriggers of the building is planned carefully. Such outriggers have a tendency to reduce the wind induced acceleration to reasonably low levels and hence become a useful feature despite the extra cost involved
\end{abstract}

Keywords: Transfer floor, Thick plates

\section{Introduction}

When considering the present situation of the country, the land becomes a scare resource. So every bit of land is precious and it is used for some important purpose. Thus, high rise apartment buildings are in demand. The current trend is to use the whole land for the structure and provide several parking floors within the building rather than providing parking outside. The column grid of an apartment floor will generally not match that of a parking floor, which gives rise to the issue of connecting the two sets of columns together.

There are several ways of connecting the two floors. Either girders or plates can be used as the transfer system. These transfer floors are difficult to design and cost a vast sum of money. Use of transfer girders is the most straightforward solution for transfer floors, but there may be many construction difficulties. Thus, this research mainly focuses on the use of a thick plate for transfer which would be easier to construct.

One particular feature of apartment buildings when compared to commercial buildings is that they have a lesser number of lifts due to lower levels of service generally provided than in an office building (Smith, 1991). Therefore when a structural system of 3D reinforced concrete frames with shear walls is used as often done in Sri Lanka, lateral stability may not be enough by just providing shear walls around lifts and stair wells specially with respect to controlling the wind induced acceleration. Often, other means such as outriggers may be needed to provide additional lateral stability in tall buildings of 3040 storey range. However, the presence of a transfer plate may be effectively used for controlling the lateral behaviour to a certain extent. This is investigated in detail in this research.

\section{Objective}

The objective of this research is to determine the effectiveness of a thick plate for transfer and its influence on the lateral behaviour of the structure. Determination of a proper way to model a thick transfer plate in finite element will also be investigated.

\section{Methodology}

First, a typical apartment layout and a parking layout were selected that satisfied the building and parking regulations (Building Regulations 1999). Particular attention was paid to select the two plans in such a way that their column grids closely resembled those in practical use at

Eng. (Prof.) M.T.R. Jayasinghe ,B.Sc. Eng (Moratuwa), Ph.D (Cambridge), C.Eng., MIE(SL, )Professor, Department of Civil Engineering, University of Moratuwa.

S.S. Balasuriya, K.M.K. Bandara, S.D. Ekanayake; Final year students, Department ofCivil Engineering, University of Moratuwa. 
present. The effect of other changes to the parking floor layout will be studied later.

The analysis was done based on a finite element model in SAP2000. Changes were made to the basic model to study the effects of different meshing techniques. Thus, two models were created with Model A having a coarse mesh in the transfer plate with Model B having a fine mesh. A third model, $\mathrm{C}$ was created with the same building height but with apartment levels from ground floor to roof only (without the need for a transfer plate since no car parking was provided). Comparison with this model will yield the effectiveness of the thick plate as an outrigger. Lateral stability was measured in terms of fundamental period of vibration, wind induced acceleration and deflection for wind loads. The wind load analysis was carried out based on loads evaluated from AS1170.2-1989 as it enables calculation of dynamic wind responses including acceleration.

\section{An overview about apartment buildings}

\subsection{General layout}

Most modern high-rise structures that are used as apartment buildings in Sri Lanka follow a regular pattern. Many such buildings consist of concrete walls which are part of the partition walls. Due to the advancement of architectural features in modern day buildings, most structural elements are provided in a manner such that they will not obstruct the spaces within the building. As a result, a regular column grid is not present in the residential areas of the apartment building as such a column grid often violates the architectural features.

Some layouts of typical apartment buildings are shown in Figure 1. They reflect the facts mentioned above and highlight the point that using concrete walls with short beams will preserve the architectural qualities.

\subsection{Car parking regulations}

It is necessary to allow space for vehicle turning circles, parking stalls, ramps, driveways, etc, when arranging a parking floor. This must be done satisfying the parking regulations in Sri Lanka. As a result, the vertical load carrying members should have a certain grid requirement. Columns are the most suitable structural elements to transfer vertical loads and the dimensions of a suitable column grid are largely dependent on the parking regulations.

This section mainly focus on the relevant regulations for standard vehicle type as indicated in Table 1 (Car Equivalent, also to be used for two and three wheelers), since multistorey car parks in apartment buildings mainly contain of those vehicle types. Other requirements are given in Table 2 and 3.

Table 1 - Minimum plan dimensions of parking stalls (Building Regulations, 1999)

\begin{tabular}{|l|c|c|}
\hline Vehicle Type & $\begin{array}{c}\text { Stall width } \\
\text { (m) }\end{array}$ & $\begin{array}{c}\text { Stall length } \\
\text { (m) }\end{array}$ \\
\hline $\begin{array}{l}\text { Standard } \\
\text { (Car Equivalent, also } \\
\text { to be used for two and } \\
\text { three wheelers) }\end{array}$ & 2.4 & 4.8 \\
\hline
\end{tabular}

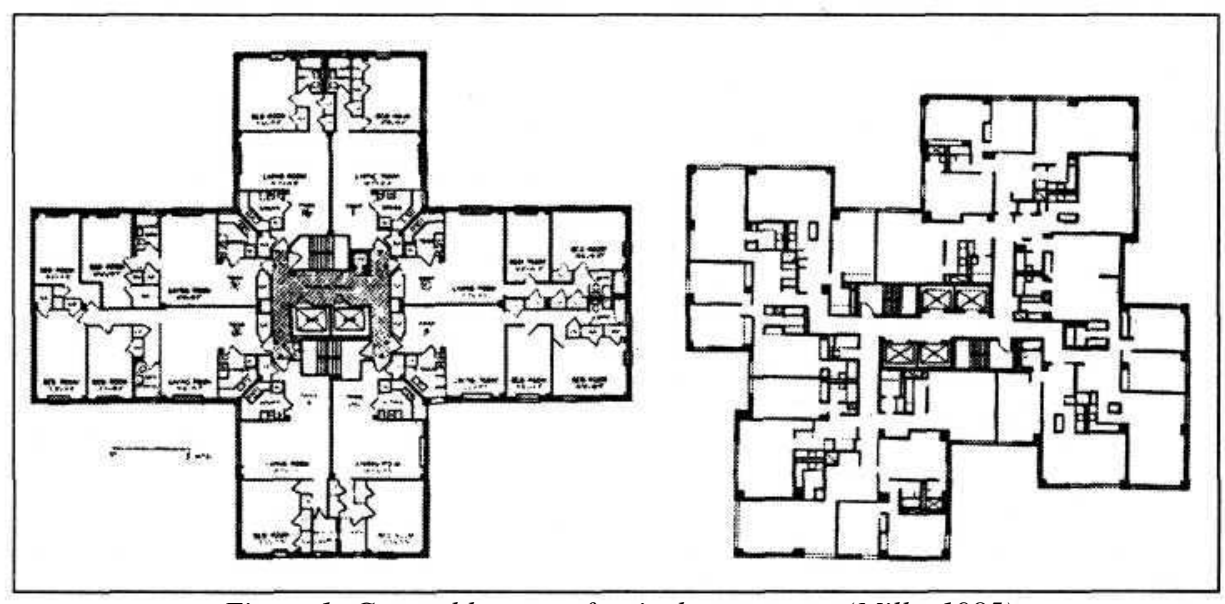

Figure 1: General layouts of typical apartments (Mills, 1985) 
Table 2 - Minimum width of aisles (Building Regulations, 1999)

\begin{tabular}{|l|c|c|c|}
\hline $\begin{array}{c}\text { Parking Angle } \\
(\text { Degree's) }\end{array}$ & $\begin{array}{c}\text { One-way } \\
\text { traffic } \\
\text { one sided } \\
\text { bays (m) }\end{array}$ & $\begin{array}{c}\text { One way } \\
\text { traffic two } \\
\text { sided bays } \\
(\mathrm{m})\end{array}$ & $\begin{array}{c}\text { Two-way } \\
\text { traffic } \\
(\mathrm{m})\end{array}$ \\
\hline $\mathbf{0 0}^{\circ}$ Parallel & 3.6 & $3 ' .6$ & 6.0 \\
$3^{\circ}$ Angle & 3.6 & 4.2 & 6.0 \\
$4^{\circ}$ Angle & 4.2 & 4.8 & 6.2 \\
$6^{\circ}$ Angle & 4.8 & 4.8 & 6.4 \\
$90^{\circ}$ Angle & 6.0 & 6.0 & 6.0 \\
\hline
\end{tabular}

Table 3 - Minimum inner and outer turning radius (Building Regulations 1999)

\begin{tabular}{|l|c|}
\hline & Passengor Car \\
\hline Inner turning radius (m) & 7.3 \\
Outer turning radius (m) & 4.7 \\
\hline
\end{tabular}

Some typical car parking arrangements are shown in Figure 2. According to those arrangements, it is evident that spacing of columns fall within a regular pattern mainly due to the clearance required for drive ways and parking bays. In addition, there are ramp arrangements needed for access to upper floors. The possible arrangements are shown in Figure 2.

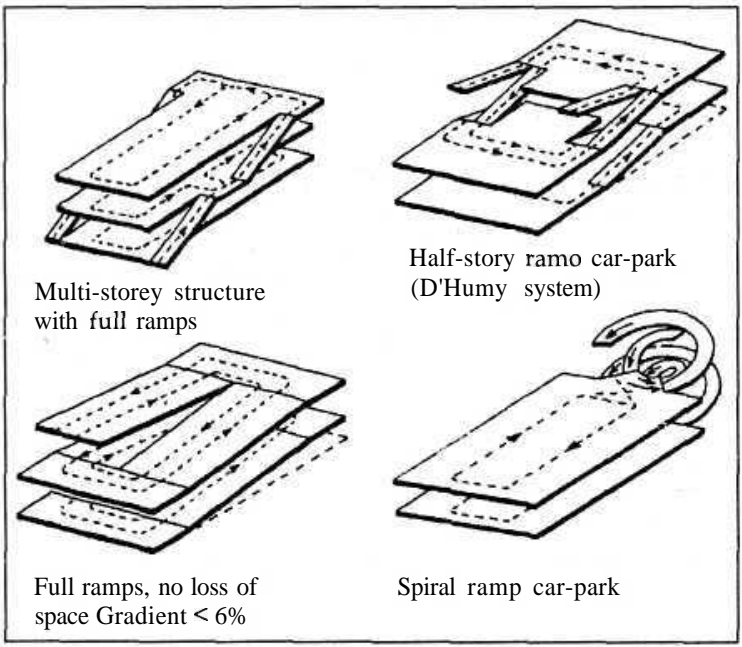

Figure 2: General layouts of parking arrangements (Neufert, 1980)

\subsection{The need for different grids}

To cater to the different needs of the apartment floors as well as to the parking floors, it is necessary to have different grids in the same structure. According to the building regulations and traffic regulations, there are some specific space allocations for those floors. In order to keep those, different grid systems are used in the same structure.

\subsection{Solution with transfer members}

For a typical apartment building shown below, it is possible to have either a transfer plate or transfer girders as the solution.

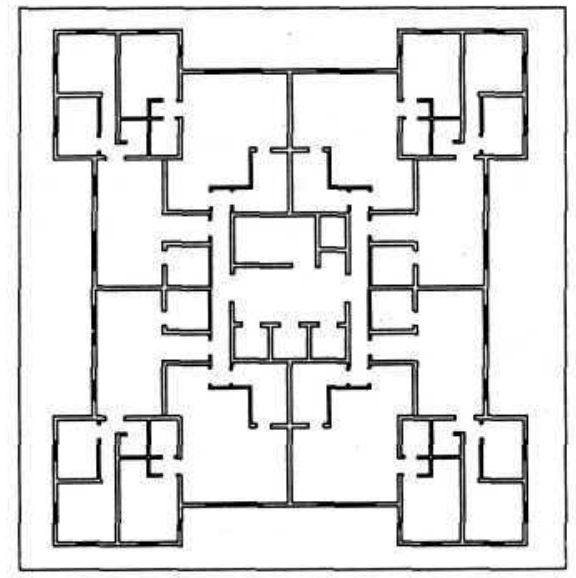

Figure 3: General architectural drawingfor apartment floors

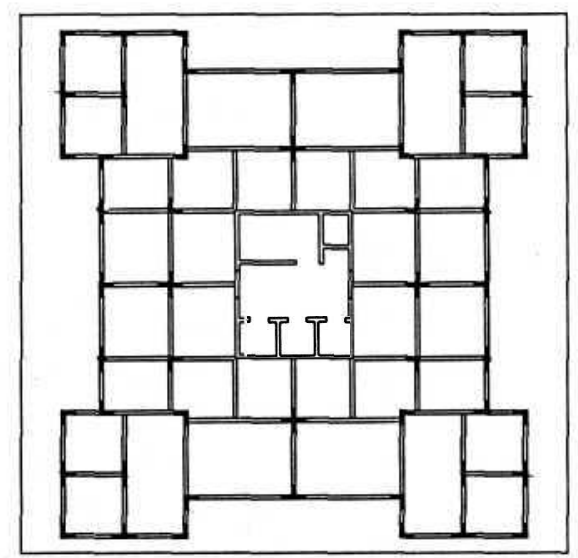

Figure 4: Column layoutfor apartmentfloors

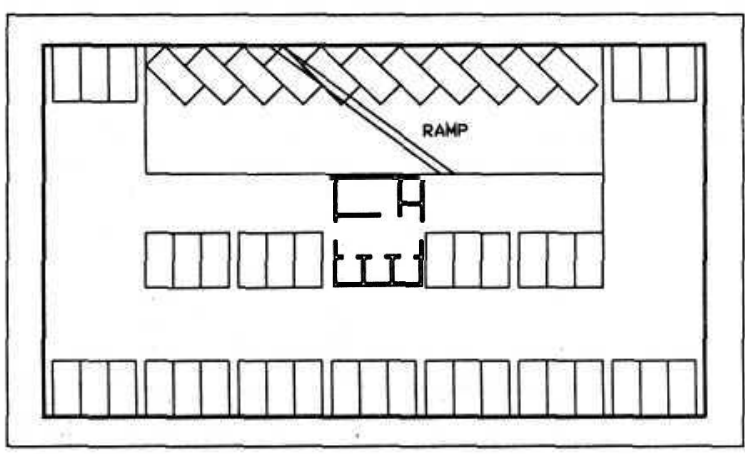

Figure 5: General architectural drawing for parking floors

\subsubsection{Solution with transfer plates}

A transfer plate is similar to a flat slab, of high thickness, often in the range of $1.0 \mathrm{~m}$. With suitable reinforcement for shear and flexure, such a thick plate can withstand the large point 


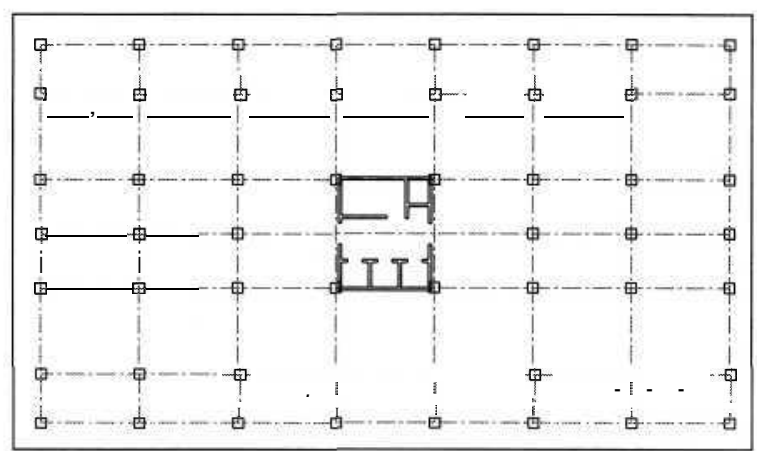

Figure 6: Column layoutfor parkingfloors

loads from the columns above. This may be the better solution since the wide scatter of columns above transfer plate could be accommodated easily as shown in Figure 7.

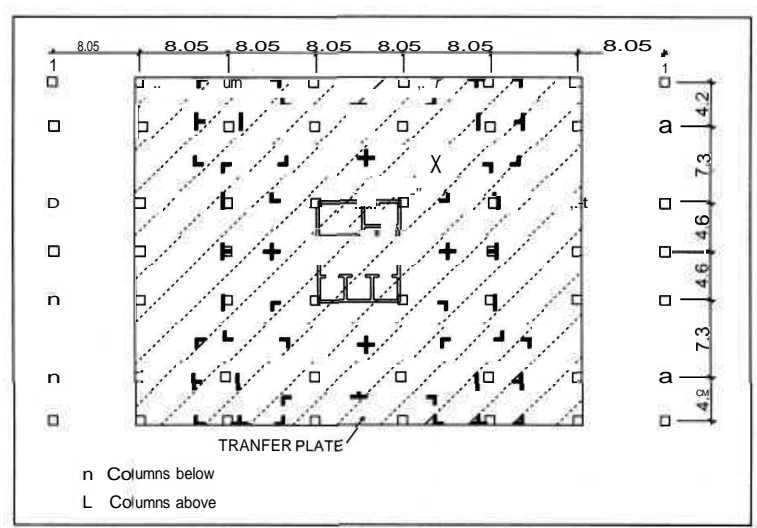

Figure 7: Transfeplate indicating the location of columns above and below

\subsubsection{Solution with transfer girders}

This is a more complicated arrangement which needs a grid of beams as shown in Figure 8. The designer must propose a suitable layout of beams with at least one beam below each column that has to be transferred.

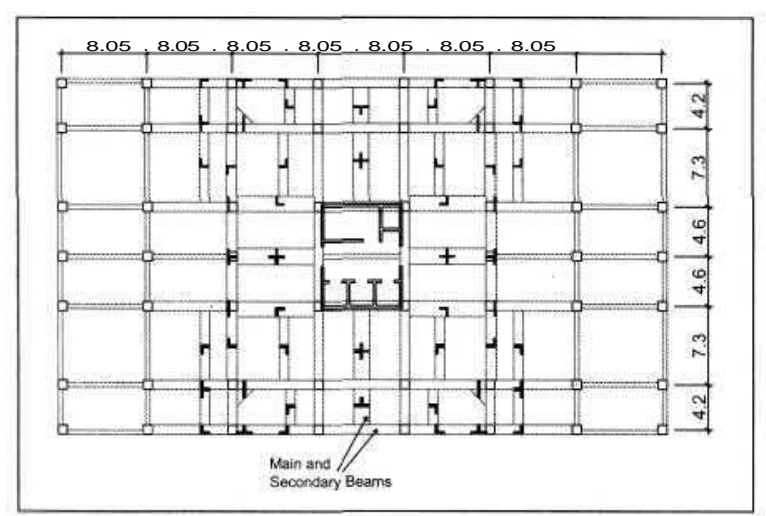

Figure 8: Transfer girders indicating the complex arrangement thatmaybeneeded

\section{Case study for 30 storey apartment building}

In order to perform a detailed study, the building of Figures 3 to 6 was selected as the building under consideration.

\subsection{Layout}

The layout below the transfer plate is shown in Figure 5, the corresponding column layout is shown in Figure 6.

The layout above the transfer plate and the corresponding column layout are shown in Figures 3 and 4, respectively. A transfer plate of thickness $1.0 \mathrm{~m}$ was used as the transfer member. Concrete of grade 40 was used in the model

\subsection{Transfer plate with SAP2000 model}

When transfer plates are modelled using shell elements, the connectivity of columns/walls above the transfer plate to column below is an important consideration. Therefore, it is advisable to create the finite element mesh with plate elements manually, ensuring that plate elements would be of acceptable proportions, avoiding situations such as excessively elongated members. This can be considered as a coarse mesh as shown in Figure 9.

Once the coarse mesh is created, SAP2000 offer a facility to mesh it further as shown in Figure 10 so that it would result in a finer mesh that may be able to provide results of higher accuracy, although it is likely to consume more computer power or take longer for analysis.

\subsubsection{Without mesh}

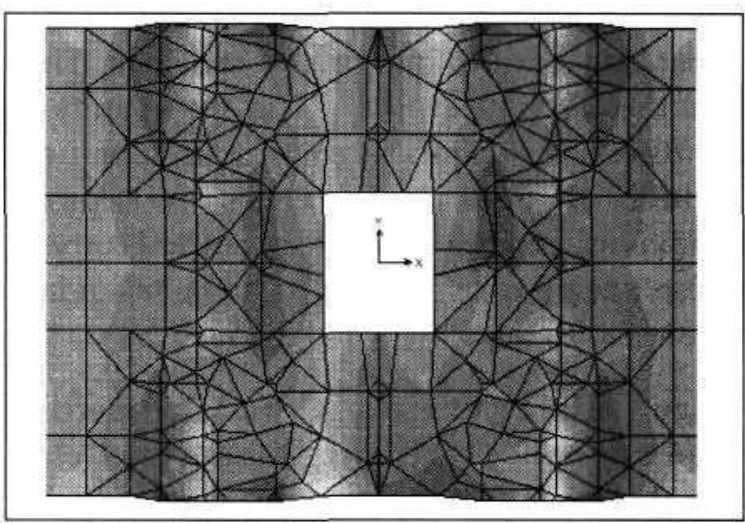

Figure 9: The coarse mesh createdfor the transfer plate (Model A) 


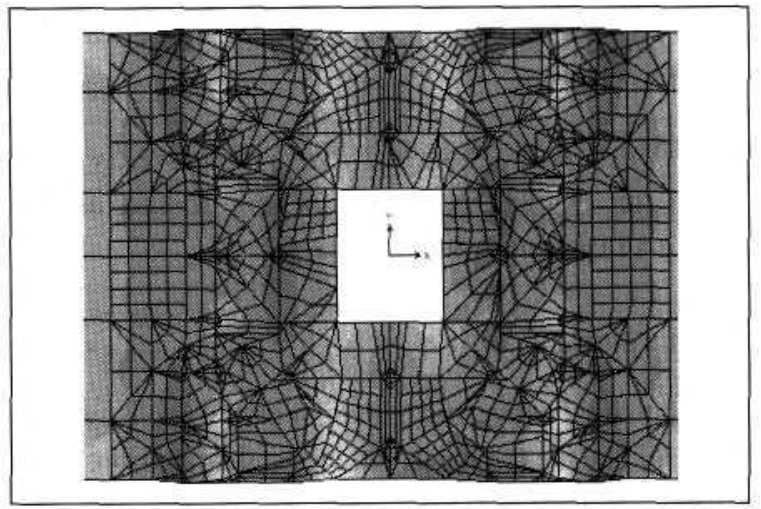

Figure 10: Fine mesh created by sub-dividing the coarse mesh (Model B)

\subsection{The mesh type}

First of all, a finite element must be selected to correctly represent the behaviour of the transfer plate. Either solid elements or shell elements can be selected (See Figure 11). Solid elements are very tedious to work with and will not be used at this stage of the research. However, there are certain issues when using shell elements. The heights of the stories above and below the transfer level must be increased to maintain the overall height of the structure. Another concern of using shell elements for this situation is that of shearing deformations.

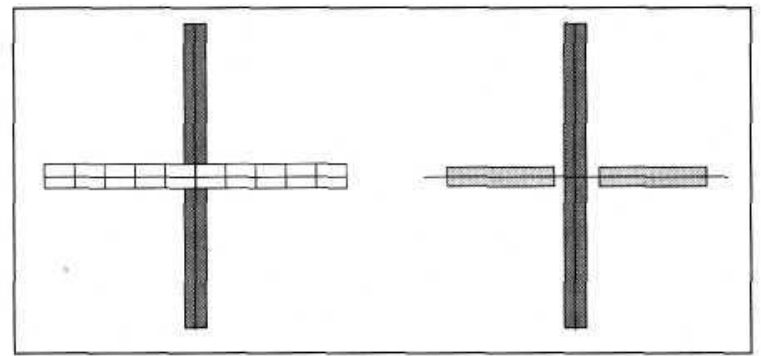

Figure 11: Using solid elements and shell elements

Shearing deformations tend to be important when the thickness of the element is greater than about one-tenth to one-fifth of the span. They can also be quite significant in the vicinity of bending-stress concentrations, such as near sudden changes in thickness or support conditions, and near holes or re-entrant corners. These, shearing deformations can be taken into account as follows:

When defining the shell element properties, there is an option of selecting either a thick-plate or a thin-plate. This governs the way thickness is formulated (This determines whether or not transverse shearing deformations are included in the plate-bending behaviour of a plate or shell element).

- The thick-plate (Mindlin/Reissner) formulation, includes the effects of transverse shear deformation

- The thin-plate(Kirchhoff) formulation neglects transverse shearing deformation

Thus, the thick-plate formulation can be used to represent the transfer plate. However, the accuracy of the thick-plate formulation is more sensitive to large aspect ratios and mesh distortion than is the thin-plate formulation. (SAP2000 Analysis reference, 2002) This factor has an important role to play and will be discussed under the section on meshing of shell elements.

Creating a model of the transfer plate is no major task if an advanced finite element package such as SAP2000 is at hand. However, there are certain aspects that the designer must be aware of in this situation. All shell elements must be properly connected to adjoining elements to have proper connectivity. If this fundamental law of finite element theory is violated, a continuous stress flow as shown in Figures 9, 10 and 12 will not be obtained. It is also important to have the local axis of all elements in the same global orientation as any deviation from this will imply difficulty when interpreting the output of shell elements. As for modelling the transfer plate itself, once the different column grids are in place they can be connected with the shell elements maintaining connectivity and keeping the orientation.

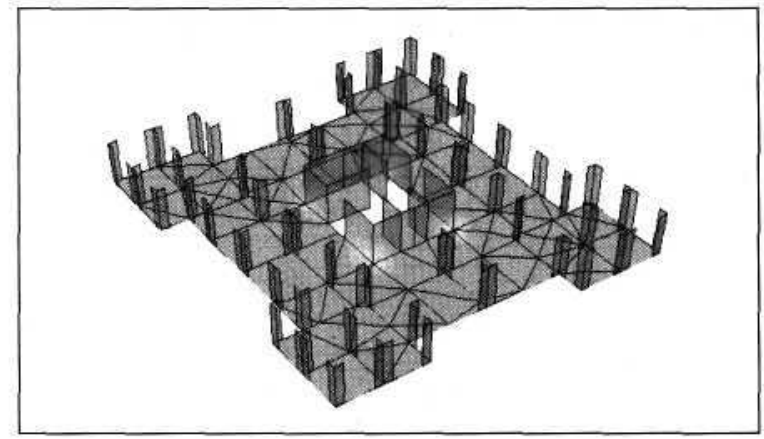

Figure 12: Continuous stressflow in shell elements

\subsection{Meshing for better results}

In any finite element model, a finer mesh may provide a more accurate result. This is particularly important in this situation as 
concentrations of stress are most likely around the columns that are transferred. Furthermore, as explained earlier, the use of the thick-plate formulation implies that the shell elements are more sensitive to large aspect ratios. If a coarse mesh is to be used, elements with large aspect ratios are most likely particularly in the vicinity of the point loads (columns that are transferred).

This implies that the shell stresses output may be slightly inaccurate in locations where it is most critical. Thus, some form of mesh refinement is necessary particularly near the point loads. The behaviour of a fine mesh and a coarse mesh is shown in Figure 13.

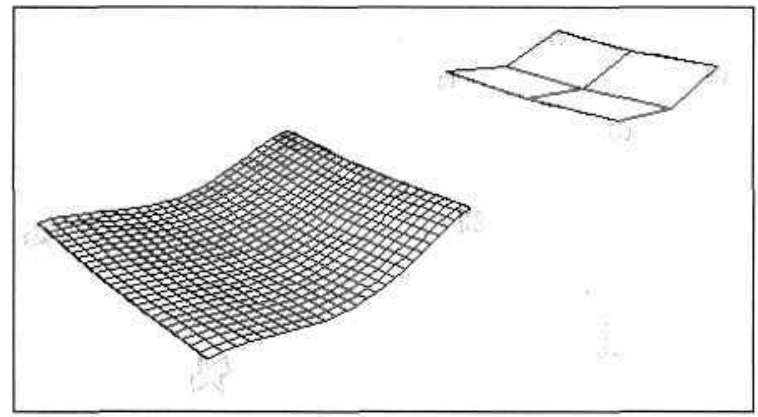

Figure 13: The behaviour of a fine mesh and a coarse mesh

5.5 Wind loads

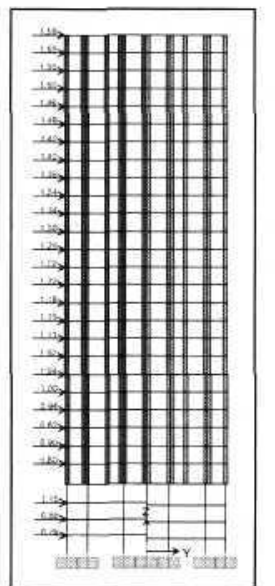

Figure 14: Wind load application

Wind load calculations were carried out according to AS1170.2-1989, for 3 second gust velocity of $33.0 \mathrm{~m} / \mathrm{s}$ (Macks et al, 1979) considering a building in zone 3 of Sri Lanka. The dynamic wind pressure was applied on the models and maximum deflections were obtained using the gust factor. This enabled the calculation of wind induced acceleration. Calculations for the wind load are included in appendix A.

\subsection{Results of analysis}

From the results in Table 4, it can be seen that there is no major differences between using a finer mesh and a coarse mesh. It can also be seen that lateral deflections are fairly low at roof level. However the maximum vertical deflections may not correctly reflect the overall picture, with the average value being about 10 $11 \mathrm{~mm}$. The real advantage of a finer mesh will be with the accuracy of the forces and moments in the transfer plate.

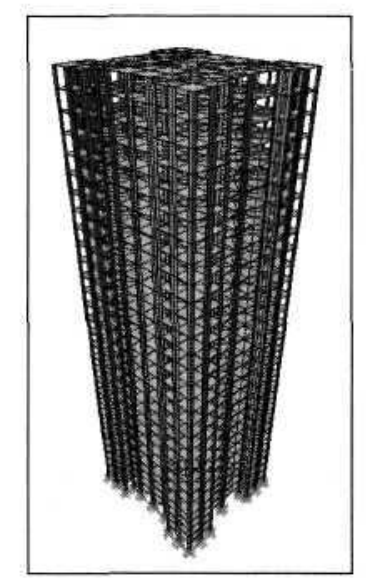

Figure 15: Model C (Without transfer plate)

When comparing results from model $\mathrm{A}$ and model $\mathrm{C}$, the effectiveness of the thick plate in reducing lateral deflections is clear. It can also be seen that lateral deflection of the plate itself is close to zero. It should be noted that wind induced accelerations have been reduced due to this outrigger action of the thick plate. People who are sensitive to movements would be able to feel acceleration above $0.05 \mathrm{~m} / \mathrm{s}^{2}$. Majority of

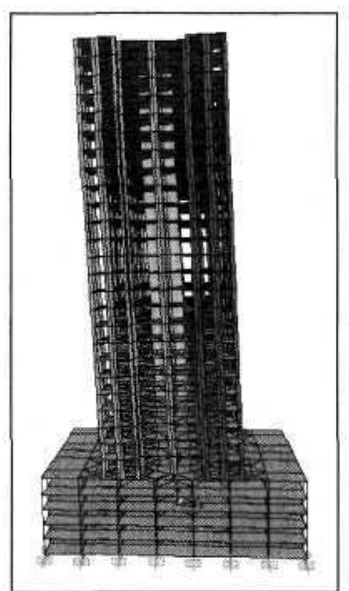

Figure 16: Fundamental vibration mode $T=2.24 \mathrm{~s}($ Model $\mathrm{A})$ 
Table 4 - Analysis results ${ }^{\dagger}$

\begin{tabular}{|l|l|l|l|l|}
\hline \multicolumn{2}{|c|}{ Parameter } & Model A & Model B & Model C \\
\hline \multicolumn{2}{|l|}{ Mesh coarseness } & coarse & fine & \\
\hline Fundamental period & of vibration & $2.24 \mathrm{~s}$ & $2.24 \mathrm{~s}$ & $2.24 \mathrm{~s}$ \\
\hline \multirow{3}{*}{ At roof level } & Maximum lateral deflection & $26.15 \mathrm{~mm}$ & $26.27 \mathrm{~mm}$ & $29.57 \mathrm{~mm}$ \\
\cline { 2 - 5 } & Average lateral deflection & $22.48 \mathrm{~mm}$ & $22.56 \mathrm{~mm}$ & $28.27 \mathrm{~mm}$ \\
\hline \multirow{3}{*}{ Transfer plate } & Max vertical deflection & $23.52 \mathrm{~mm}$ & $24.04 \mathrm{~mm}$ & $7.81 \mathrm{~mm}^{*}$ \\
\cline { 2 - 5 } & Average vertical deflection & $10.20 \mathrm{~mm}$ & $11.01 \mathrm{~mm}$ & $5.91 \mathrm{~mm}^{*}$ \\
\cline { 2 - 5 } & Maximum lateral deflection & $2.42 \mathrm{~mm}$ & $2.47 \mathrm{~mm}$ & $2.93 \mathrm{~mm}^{*}$ \\
\cline { 2 - 5 } & Average lateral deflection & $2.19 \mathrm{~mm}$ & $2.25 \mathrm{~mm}$ & $2.68 \mathrm{~mm}^{\prime}$ \\
\cline { 2 - 5 } & Along wind acceleration & $0.1058 \mathrm{~m} / \mathrm{s}^{2}$ & $0.1063 \mathrm{~m} / \mathrm{s}^{2}$ & $0.1197 \mathrm{~m} / \mathrm{s}^{2}$ \\
\hline
\end{tabular}

* - These deflection values are obtained at the same level as the transfer level

$\mathrm{t}$ - Vertical deflections are for $1.4 G_{k}+1.6 Q_{k}$ load case and lateral deflections are for $1.0 G_{k}+1.4 W_{k}$ load case.

the people will feel accelerations of about $0.1 \mathrm{~m} /$ $\mathrm{s}^{2}$ (Smith \& Coull, 1991). This means, even the small reduction in acceleration that can be achieved in apartment buildings would be important because people will be living in them.

When closely inspecting the fundamental vibration mode in Figure 16, it seems that the apartment above the transfer plate contributes much more than the structure below the transfer plate as lateral deflections of the transfer plate and below are at a minimum. Effectively, the apartment structure behaves as if it is supported on a rigid foundation, at the level of the transfer plate.

\section{Conclusions}

It can be concluded that the transfer plates can be used effectively as outriggers in apartment buildings. A proper finite element molel will yield the required design parameters for the transfer plate itself and parameters regarding the lateral behaviour of the structure. This reduction in lateral deformation to almost zero at the transfer plate level could lead to a reduction in lateral deflection at the top of the building. This can reduce the peak wind acceleration values. This could be extremely valuable in apartment buildings that are designed with a greater height due to the need for accommodating car parking needs. The provision of acceptable level of occupant comfort is one of the primary responsibilities of the structural design engineer.

\section{References}

1. AS1170.2-1989, "Minimum design loads on structures- Part 2: Wind loads", Standards Australia, New South Wales.

2. Building Regulations (1999), City of Colombo Development Plan, Volume II, Colombo Municipal Council.

3. Neufert, Architects' data, Blackwell Scientific Publications 1980, p. 252

4. Macks, K. \}., Murray, F. J., Wittenoom, R. A. (1979), "TechnicalAssistance to Sri Lanka on cyclone resistance construction", Vol. 2, Part 5, Australian Development assistance Bureau, Department of Housing and Construction, Australia.

5. Mills, Planning Architects Hand Book, 10th ed., Butterworths, 1985.

6. SAP2000 Analysis reference, Computers and Structures, Inc., Berkeley, Califonia, USA, Version 8.0.July 2002.

7. Smith, B. S., Coull, A.,(1991), "Tall Building Structures", John Wiley, USA, pp. 537.

8. Smith, P. R., (1991), "The movement of people and goods", In Handbook of Architectural Technology, edited by J. Cowan, VAN Nostrand Reinhold, New York, 1991, pp. 423-440. 


\section{Appendix}

Dynamic wind load calculation (According to AS 1170.2 - 1989)

\section{Calculation of Gust factor (G)}

Basic wind speed (V) $=33.0 \mathrm{~m} / \mathrm{s}$

Height of the building (h)

Natural period of vibration of the building

Estimated natural frequency (na) $=0.43 \mathrm{~Hz}$

Clause 4.4.2.

$$
\begin{aligned}
& G=1+r \sqrt{\left[g_{v}^{2} B(1+w)^{2}+\frac{g_{f}^{2} S E}{\zeta}\right]} \\
& \mathrm{r}=\frac{2\left[\frac{\sigma_{\mathrm{v}}}{\overline{\mathrm{V}} \mathrm{J}}\right.}{\overline{\mathrm{M}}_{\mathrm{t}}}=\frac{2 \times 0.166}{1.0}=0.352 \\
& \mathrm{~g}_{\mathrm{v}}=3.7 \\
& \mathrm{~g}_{\mathrm{f}}=\sqrt{2 \log _{\mathrm{e}}\left(3600 \mathrm{n}_{\mathrm{a}}\right)} \\
& =\sqrt{2 \log _{e}(3600 \times 0.43)}=3.83 \\
& \overline{\mathrm{V}}_{\mathrm{h}}=\mathrm{V}_{\mathrm{M}} \overline{\mathrm{h}}_{\mathrm{c} \text { cat })} \mathrm{M}_{\mathrm{s}} \overline{\mathrm{M}}_{\mathrm{t}} \mathrm{M}_{\mathrm{i}} \\
& =33.0 \times 0.72 \times 1.0 \times 1.0 \times 1.0=23.76 \mathrm{~m} / \mathrm{s} \\
& \mathrm{S}=\frac{1}{\left[1+\frac{3.5 \mathrm{n}_{\mathrm{a}} \mathrm{h}}{\overline{\mathrm{V}}_{\mathrm{h}}}\right] \overline{\left[1+\frac{4 \mathrm{n}_{\mathrm{a}} \mathrm{b}}{\overline{\mathrm{V}}_{\mathrm{h}}}\right]}} \\
& =\frac{1}{\left[1+\frac{3.5 \times 0.43 \times 104.2}{23.76}\right]\left[1+\frac{4 \times 0.43 \times 30.0}{23.76}\right]}=0.0413 \\
& E=\frac{0.47 N}{\left(2+N^{2}\right)^{5 / 6}}, \quad N=\frac{n_{a} L_{h}}{\bar{V}_{h}}, \quad L_{h}=1000\left[\frac{h}{10}\right]^{0.25} \\
& \mathrm{~L}_{\mathrm{h}}=1000\left[\frac{104.6}{10 \mathrm{~J}}^{0.25}=1798.39\right. \\
& \mathrm{N}={ }^{0.43 \times 1798.39} \cdot \mathbf{2 3 . 7 6}=32.55 \\
& \text { E } \begin{array}{l}
0.47 \times 32.55 ; i \\
\left(2+32.55^{2}\right)^{5 / 6}
\end{array}=0.046 \\
& \zeta=0.01 \\
& B=\frac{1}{1+\frac{\sqrt{36 h^{2}+64 b^{2}}}{L_{h}}} \\
& =\frac{1}{1+\frac{\sqrt{36 \times 104.2^{2}+64 \times 30.0^{2}}}{1798.39}}=0.728
\end{aligned}
$$

$$
\begin{array}{r}
\mathrm{w}=\frac{\mathrm{g}_{\mathrm{v}} \mathrm{r} \sqrt{\mathrm{B}}}{4}=\frac{3.7 \times 0.332 \times \sqrt{0.728}}{4}=0251 \\
\mathrm{G}=1+0.332\left(3.7^{2} \times 0.728 \times(1+0.254)^{2}\right. \\
\left.+\frac{3.83^{2} \times 0.0413 \times 0.046}{0.046}\right]^{1 / 2}
\end{array}
$$

$\underline{\mathrm{G}=2.426}$

\section{Calculation of wind loads on the building}

$\overline{\mathrm{F}}_{\mathrm{z}}=\mathrm{C}_{\mathrm{p}, \mathrm{e}} \overline{\mathrm{q}}_{\mathrm{z}} \mathrm{A}_{\mathrm{z}}$

$C_{p, \epsilon}$ for windward wall $=0.8$

$\mathrm{C}_{\mathrm{p}, \mathrm{e}}$ for leeward wall $=-0.483$

Specimen calculation for $\mathrm{Z}=6.6 \mathrm{~m}$

$$
\begin{aligned}
\overline{\mathrm{V}}_{\mathrm{z}} & =\mathrm{V} \overline{\mathrm{M}}_{(\mathrm{z}, \mathrm{cat})} \mathrm{M}_{\mathrm{s}} \overline{\mathrm{M}}_{\mathrm{t}} \mathrm{M}_{\mathrm{i}} \\
& =33.0 \times 0.4 \times 1.0 \times 1.0 \times 1.0=13.2 \mathrm{~m} / \mathrm{s} \\
\mathrm{q}_{\mathrm{z}} & =0.6 \overline{\mathrm{V}}_{-}^{2} \times 10^{-3}=0.6 \times 13.2^{2} \times 10^{-3}=0.105 \mathrm{kPa} \\
\mathrm{F}_{\mathrm{z}} & =[(0.8)-(-0.483)] \times 0.105 \times(3.3 \times \mathrm{xl})=0.44 \mathrm{kN} / \mathrm{m}
\end{aligned}
$$

Lateral deflection at roof level (A) was obtained from the model considering the following load combination:

$1.0 \mathrm{~g}_{\mathrm{k}}+1.4 \mathrm{GW}_{\mathrm{k}}=1.0 \mathrm{~g}_{\mathrm{k}}+1.4 \times 2.426 \times$ Average loads Where $\mathrm{G}=$ gust factor $=2.426$

\section{Along wind acceleration $\left(a_{a}\right)$}

$$
a_{a}=\left(2 \pi n_{a}\right)^{2} g_{f} r \underset{V}{I} \frac{I S P}{S} A
$$

For model A

$$
\begin{aligned}
a_{a} & =(2 \pi \times 0.43)^{2} \times 3.83 \times 0.332 \sqrt{\frac{0.0413 \times 0.046}{0.01}} \Delta \\
& =0.1058 \mathrm{~m} / \mathrm{s}
\end{aligned}
$$

For model B

$$
\alpha_{\mathrm{a}}=0.1063 \mathrm{~m} / \mathrm{s}
$$

For model C

$$
\alpha_{\mathrm{a}}=0.1197 \mathrm{~m} / \mathrm{s}
$$


Table A.1 : Wind loads at each floor level (in kN/m)

\begin{tabular}{|c|c|c|c|c|c|c|c|}
\hline Level & $\begin{array}{c}\text { Floor to floor } \\
\text { height }(\mathrm{m})\end{array}$ & $\mathrm{Z}(\mathrm{m})$ & $\begin{array}{l}\text { Effective } \\
\text { height }(m)\end{array}$ & $M_{(z, c a t)}$ & $\bar{V}_{z}$ & $\bar{q}_{z}(\mathrm{kPa})$ & $\overline{\boldsymbol{F}}_{z}(k N / m)$ \\
\hline $\mathrm{G}$ & 3.3 & 0 & 1.65 & & & & \\
\hline 1 & 3.3 & 3.3 & 3.3 & 0.38 & 12.54 & 0.094 & 0.40 \\
\hline 2 & 3.3 & 6.6 & 3.3 & 0.4 & 13.2 & 0.105 & 0.44 \\
\hline 3 & 3.8 & 9.9 & 3.55 & 0.44 & 14.52 & 0.126 & 0.57 \\
\hline 4 & 4.1 & 13.7 & 3.55 & 0.48 & 15.84 & 0.151 & 0.69 \\
\hline 5 & 3.6 & 17.8 & 3.7 & 0.51 & 16.83 & 0.170 & 0.81 \\
\hline 6 & 3.6 & 21.4 & 3.85 & 0.53 & 17.49 & 0.184 & 0.91 \\
\hline 7 & 3.6 & 25 & 3.6 & 0.54 & 17.82 & 0.191 & 0.88 \\
\hline 8 & 3.6 & 28.6 & 3.6 & 0.56 & 18.48 & 0.205 & 0.95 \\
\hline 9 & 3.6 & 32.2 & 3.6 & 0.58 & 19.14 & 0.220 & 1.02 \\
\hline 10 & 3.6 & 35.8 & 3.6 & 0.59 & 19.47 & 0.227 & 1.05 \\
\hline 11 & 3.6 & 39.4 & 3.6 & 0.6 & 19.8 & 0.235 & 1.09 \\
\hline 12 & 3.6 & 43 & 3.6 & 0.61 & 20.13 & 0.243 & 1.12 \\
\hline 13 & 3.6 & 46.6 & 3.6 & 0.62 & 20.46 & 0.251 & 1.16 \\
\hline 14 & 3.6 & 50.2 & 3.6 & 0.63 & 20.79 & 0.259 & 1.20 \\
\hline 15 & 3.6 & 53.8 & 3.6 & 0.64 & 21.12 & 0.268 & 1.24 \\
\hline 16 & 3.6 & 57.4 & 3.6 & 0.64 & 21.12 & 0.268 & 1.24 \\
\hline 17 & 3.6 & $61^{\circ}$ & 3.6 & 0.65 & 21.45 & 0.276 & 1.27 \\
\hline 18 & 3.6 & 64.6 & 3.6 & 0.66 & 21.78 & 0.285 & 1.32 \\
\hline 19 & 3.6 & 68.2 & 3.6 & 0.67 & 22.11 & 0.293 & 1.35 \\
\hline 20 & 3.6 & 71.8 & 3.6 & 0.67 & 22.11 & 0.293 & 1.35 \\
\hline 21 & 3.6 & 75.4 & 3.6 & 0.68 & 22.44 & 0.302 & 1.40 \\
\hline 22 & 3,6 & 79 & 3.6 & 0.69 & 22.77 & 0.311 & 1.44 \\
\hline 23 & 3.6 & 82.6 & 3.6 & 0.69 & 22.77 & 0.311 & 1.44 \\
\hline 24 & 3,6 & 86.2 & 3.6 & 0.7 & 23.1 & 0.320 & 1.48 \\
\hline 25 & 3.6 & 89.8 & 3.6 & 0.7 & 23.1 & 0.320 & 1.48 \\
\hline 26 & 3.6 & 93.4 & 3.6 & 0.71 & 23.43 & 0.329 & 1.52 \\
\hline 27 & 3.6 & 97 & 3.6 & 0.72 & 23.76 & 0.339 & 1.57 \\
\hline 28 & 3.6 & 100.6 & 3.6 & 0.72 & 23.76 & 0.339 & 1.57 \\
\hline 29 & 3.6 & 104.2 & 3.6 & 0.73 & 24.09 & 0.348 & 1.61 \\
\hline
\end{tabular}

